\title{
THE CASE OF CASE STUDY METHODOLOGY WITH ACTOR NETWORK THEORY
}

\section{Samar Elsayad ${ }^{1}$}

\begin{abstract}
This paper is a by-product of my unpublished $\mathrm{PhD}$ thesis which I submitted to the University of Glasgow, United Kingdom, and obtained my PhD in 2016. When I first joined the University of Hull to pursue my PhD studies under the supervision of Danture Wickramasinge, I was astonished by hearing that a social theory can be used in doing a management accounting research. When Dan joined the University of Glasgow, I followed his foot-step and joined Glasgow with my desire to follow that novel tradition of research. In this paper, I illustrate how Bruno Latour and his follows' ideas of Actor-Network Theory (ANT) challenged my way of thinking, informed my way of doing research, shaped my analytical instruments. I hope this illustration may guide emerging researchers who want to take a constructionist approach to management and accounting research which ANT has promoted, enacted and popularised around the globe.
\end{abstract}

\section{Introduction}

Some theories are symmetrical with methodologies, and vice versa. Some argue that ANT is of this kind. It is because in taking ANT, a researcher needs to follow both human and non-human actors to see how things such management practices are constructed in a given circumstance. When the researcher follows, he/she may see how actors network in the construction of that thing. Until the researcher finds it, knowledge of that "thing" is uncertain: ANT guides us to explore new knowledge which is always ambiguous, uncertain and unpredictable. At the same time, ANT defines what constitutes knowledge (epistemology) and provides a set of assumptions about the nature of the world's reality (ontology).

The purpose of this paper is to illustrate how my journey of $\mathrm{PhD}$ was made in relation to my intimate association with ANT. In the next section, I will start with this reflection and proceeds with how I exposed to an ontological and epistemological position that stemmed from my above association. The paper then goes on to show how I collected data around the issue of management accounting roles in the context of supply-chain management within a UK supermarket and how I analysed them using ANT. Finally, I will illustrate my assessment of research quality followed by a conclusion.

A theory that framed a methodological choice

ANT is the main theoretical framework that shapes the analysis of the four essays (especially the first three essays) and ultimately the conclusions drawn from them. Geoff Walsham noted that, quoted by Rönnbäck et al. (2007, p.1277), "theory is both a way of seeing and a way of not seeing". This thesis does not claim that ANT is the right theory or the only one theory for understanding this research, but rather it only helps to highlight

\footnotetext{
${ }^{1}$ Tanta University, Egypt
} 
certain perspectives that I aim to explore in this thesis which may not be captured by other theories. However, at the same time, I understand that this theory may blind me to other perspectives that can be detectable by using other theories.

In the first months of my PhD study, the writings of Latour (1986a; 1987; 1988b; 1996; 1999; 2005; 2008; Latour and Woolgar, 1979) and his colleauges, Callon (1986; 1991; 1993; 1999) and Law (1991; 1992; Law and Hassard, 1999), marked my journey. According to Alvesson and Sköldberg (2009,p.32), "Latour has launched a very successful methodological programme, 'the actor-network theory' (ANT), where the actors do not only need to be humans ... The idea of non-human actors can at first sight seem a bit fantastic, almost science fiction, but on a closer look it appears less bizarre". At the beginning I found Latour's idea very interesting as I used to view nonhumans as mere passive entities. Latour (1999,p.214) argues that society is characterized by "an increasingly large number of humans are mixed with an increasingly large number of nonhumans, to the point that, today, the whole planet is engaged in making of politics, law, and soon, I suspect, morality". It is not only that. ANT also supports treating humans and nonhumans symmetrically and denies any form of reductionism that assumes, a priori, that either humans or nonhumans drive the other or determine the character of social change (Law, 1992; Latour, 2005). Although Latour's ideas were very exciting for me, I was not sure whether this thinking is practical. Therefore, I started to think about my ordinary life and how it is affected by various nonhuman actors.

I remembered that while I was in Egypt I could not work on my assignment for about 3 days because the internet services had been suffering after a ship's anchor cut through undersea internet cable, and thus, I had to ask the lecturer to postpone the deadline for the assignment which means that I was influenced by this innovation. This innovation "is thus not only a passive receptor of impulses from human subjects in its initial construction but also in its turn influences human subjects" (Alvesson and Sköldberg, 2009,p.32). Also, I noticed that the choice of my research topic was influenced by the books and papers I read, my previous research experience, and my background. This made me convinced that nonhuman actors can be more active than I usually assumed and that ANT can offer me with a different view of the world.

Inspired by Latour's innovative ideas, I concluded that my thesis would trace the associations between actors (humans or nonhumans) that drive the supply chain rather than properties of supply chain. Also, as ANT has repositioned calculations as central objects in the study of social phenomena (Justesen and Mouritsen, 2011), this thesis aims to explore how accounting calculative tools act in mediating supply chain networks. To do so, various notions have been used in the essays as 'matters of concern', 'matters of fact', 'translation', 'ostensive' and 'performative' aspects. These notions will be explained later in the essays.

Although ANT has received considerable attention from many scholars in various disciplines, some scholars have raised some concerns with regard to its application. One of the main criticisms is that ANT disregards social structures that influence the local (McLean and Hassard, 2004). It "concentrates on the 'micro' at the exclusion of the 
"macro" (McLean and Hassard, 2004, p.508). Latour (1991, p.118) countered this critique by arguing that "the macro-structure of society is made of the same stuff as the micro-structure", and therefore can be investigated in much the same methodological approach. Also, Latour (2005,p.176) added that:

Macro no longer describes a wider or a larger site in which the micro would be embedded like some Russian Matryoshka doll, but another equally local, equally micro place, which is connected to many others through some medium transporting specific types of traces. No place can be said to be bigger than any other place, but some can be said to benefit from far safer connections with many more places than others. This move has the beneficial effect to keep the landscape flat, since what earlier, in the pre-relativist sociology, was situated 'above' or 'below' remains side by side and firmly on the same plane as the other loci which they were trying to overlook or include.

The idea here is that ANT does avoid the movement between the macro and the micro; it denies the distinction between them and, instead, focuses on tracing actors wherever they lead. I believe that this thinking helps researchers to freely conduct their research and see what is going on in the field without having the burden of preconception about micro and macro.

Another concern is related to the symmetrical treatment of humans and nonhumans (Amsterdamska, 1990; Collins and Yearley, 1992). Amsterdamska Amsterdamska (1990) criticised treating people and things symmetrically. She (Amsterdamska, 1990,p.501) stated that:

In what way is enrolling the microbe the same as enrolling a group of interested farmers or enrolling someone to finance a given project equivalent to the enrollment of a group of colleagues? Does each actant contribute to success or failure in the same way? Do scientists enroll electrons for the same reasons they enrol industrialists? Is the recruitment of a police force or an army equivalent to the enrollment of a group of other scientists? Does enrollment really mean the same thing in all these cases? It seems to me that the goals, the means, and the results of enrolling such different kinds of "allies" are hardly comparable, and that the elimination of differences among them leads only to confusion.

Also, Collins and Yearly (1992) questioned the practicality of treating humans and nonhumans in the same manner. Although ANT focuses on symmetrical treatment between humans and nonhumans, it does not denies that there are differences between humans and nonhumans. Law (2000,p.857) argued that:

To say that there is no fundamental differences between people and objects is an analytical stance, not an ethical position. And to say this does not mean that we have to treat the people in our lives as machines. We don't have to deny them the rights, duties, or responsibilities that we usually accord to people. 
Also, Latour (2005,p.76) explained the meaning of the symmetrical treatment by stating that:

To be symmetric, for us, simply means not to impose a priori some spurious asymmetry among human intentional action and a material world of causal relations. There are divisions one should never try to bypass, to go beyond, to try to overcome dialectically.

What clears from the above is that ANT appreciates the differences between humans and nonhumans, rather it denies a priori assumption about the importance of one actor over the other as we should first try to discover what actually determine the actions. This is consistent with what I noticed when I started to think about my ordinary life, as I mentioned before.

Although ANT is the dominating theory in this thesis, Essay 4 employs a different framework which is heterarchy that has been introduced by David Stark. There are two reasons for this. The first reason is related to the nature of category management. Category management exemplifies many of the characteristics of heterarchy such as interdependent relations and more collaborative modes of organizing, considerable heterogeneity, permeable boundaries, and multiple performance criteria which are different from traditional hierarchy (King and Phumpiu, 1996; Kellogg et al., 2006; Free, 2008; Stark et al., 2009). Presenting category management as a form of heterarchy can help in understanding this practice from different perspectives and providing new insights that has not been considered by previous research. Also, using category management as an illustrative case of heterarchy provides an opportunity for exploring how work is accomplished with such radical post-bureaucratic organization forms, the complexities prevailing in these new forms, and the implication on accounting, especially this new framework has not drawn researchers' attention yet although it is becoming more prevalent in many industries.

The second reason is that using heterarchy can add new perspective to ANT. Stark has dawn on Latour, Callon, and their colleagues to develop heterarchy which refers to the organizational forms with a capacity for reflexive cognition (Stark et al., 2009). Stark shares many of Latour's thoughts and beliefs such as symmetrical treatment of humans and nonhumans, looking at the social as a 'flat space', etc. For instance, Stark (2009,p.119) argues that "in place of studying "society" we must construct a science of associations - an analysis that examines not only links among persons but also among persons and instruments". Therefore, Heterarchy is on same line with ANT. However, Stark extended and deepen that perspective by using Boltanski and Thévenot's notion of economies of worth (Boltanski and Thévenot, 2006) to develop his heterarchy framework. According to stark "the new organizational forms are heterarchical not only because they have flattened reporting structures but also because they are the sites of heterogeneous systems of accounting for worth". This notion is used to show how organizations can have heterogeneous criteria with regard to what is right and what valuable which, in turn, requires multiple, sometimes, opposed evaluative criteria (Stark et al., 2009). According to Rona-Tas (2011,p.598), “this opens up a terrain of 
uncertainty, which demands search, inquiry, discovery and creative entrepreneurship". This can be considered one of the advantages of heterarchy as it accommodates "the creative tension between competing principles" (Rona-Tas, 2011,p.598). Using this notion can help me in understanding the perceptions of actors involved in category management regrading what is valuable, how they measure it, and how they face dissonance that emerges from conflicts between multiple principles of valuation (orders of worth) which, in turn, can deepen my analysis.

Like most other theoretical frameworks, there are some points in Stark's framework that I felt require for more development and clarification. For Stark, the interaction and conflict between different order of worth and evaluative principles facilitate innovation and creativity. However, from my point of view, this point opens up some questions that need to be answered. For instance, does this mean that single evaluative principles can't encourage innovation? Isn't it possible that the conflict between orders of worth can lead to strife rather than innovation? I hope that Stark can clarify these points in his coming books or papers; however, I believe that theorists always leave readers with puzzles.

\section{The oncological and epistemological positions}

When I started to read about ANT, it was difficult for me to classify it under a specific school of thoughts. For instance, although the two-by-two model by Burrell and Morgan (1979) made an enormous impact with regard to theoretical and methodological positions, we can't place ANT under any of the four paradigms (functionalist, interpretive, radical humanist and radical structuralist) as ANT denies the distinction between the subjective and the objective which form the basic axes in the matrix (Justesen and Mouritsen, 2011; Hassard and Wolfram Cox, 2013). Even it is difficult to classify ANT according to Ryan's categorization scheme of management accounting research (positive, interpretive, and critical) (Ryan et al., 2002). Although some researchers place ANT under interpretive research (Wickramasinghe and Alawattage, 2007), Latour denies that and states "I have no real sympathy for interpretative sociologies" (2005,p.144). This difficulty applies to defining the ontology of ANT, even; it is difficult to describe Latour himself. This may be attributed to the fact that Latour, in his recent writings (Latour, 2004a; Latour, 2004b; Latour, 2005), suggests a line of inquiry that is different from the one in his early writings (Latour, 1987; Latour, 1990; Latour and Woolgar, 1979). At the beginning Latour described himself as a constructionist, however, later described himself as being a more realist (Alvesson and Sköldberg, 2009). Instead of focusing on how facts are really constructed, Latour (2004b,p.232) argues that:

Reality is not defined by matters of fact. Matters of fact are not all that is given in experience. Matters of fact are only very partial and, I would argue, very polemical, very political renderings of matters of concern and only a subset of what could also be called states of affairs. It is this second empiricism, this return to the realist attitude, that I'd like to offer as the next task for the critically minded. [...] My question is thus: Can we devise another powerful descriptive tool that deals this time with matters of concern and whose import then will no longer be to debunk but to protect and to care [...]. Is it really possible to transform the critical urge in the ethos of someone who adds reality to matters of fact and not subtract reality? 
According to Justesen and Mouritsen (2011,p.183), "viewing the world in terms of matters of concern is, in Latour's universe, a realist approach to the world - a view that is more realist than the "matters of fact" world view because the latter reduces the thing to a mute object". From the above, we can understand why defining the ontological position of ANT is difficult, as it can be regarded as a constructivist approach or a relativist approach. This also what I learned from talking with many ANT-inspired researchers during my $\mathrm{PhD}$ journey.

Regarding this thesis, the ontological position in this thesis is both: relativist and constructivist. While the underlying ontology of Essay 1 is relativist (it utilize the notion of 'matters of concern'), the other three essays take the constructivist position as they focus on how facts are really constructed and how various, and sometimes surprising, implications are to be noted.

As an epistemological strategy of acquiring knowledge, ANT place great reliance on following the actors (humans and nonhumans) and the relations and interactions between them. According to Hassard and Wolfram (2013,p. 1711):

We contend that in its various formulations ANT exemplifies many of the assumptions of rela $\neg$ tionist epistemology [...]. In other words, epistemologically ANT has been used to con $\neg$ ceptualize, simultaneously, relations between (material) things and (semiotic) concepts. When such assumptions are reflected practically, in fieldwork, the interactions that researchers examine in an organization involve relations between people, ideas and technologies, which together can be understood to form a network.

This is what I aim to do in this thesis. I will trace the actors to explore how things come to be. This leads us to one of the key critiques to ANT which is so called inclusion/exclusion debate which is related to the decision of actors to include and actors to exclude (McLean and Hassard, 2004). Miller (1997,p.363) expressed this issue by stating that:

Who decides who the actors are? It's fine to tell us that we should believe them when they speak to us, that we should refrain from judging them, but we have to know who to speak to in the first instance, which meeting to attend, who to call on the telephone, who to e-mail, and who to ask for an interview! Who is going to provide an answer to these questions? And should we believe them too? Of course you'll reply that the answer to this question is to be found in the technological project itself, in the activities of the contextualizers. But that won't do, because it presupposes that we know the boundaries of the project at the outset. While the territory of a project may not be limitless, neither is it as clear-cut as you make out. The linkages do not just stop at a certain point.

Therefore, the problem is not only related who to include/exclude, but, also, where to cut the network. Hull (1999) raised the issue of the starting point to follow a network. He questioned "Why choose one object of study rather than another?; Why choose to start at one point and 
not another?" (Hull, 1999,p.414). However, these are not the issues of ANT alone but all research. According to Lowe (2001,p.346), "in any qualitative study it is possible to miss the point. The researcher may fail to complete the hermeneutic circle and never arrive at an empathetic understanding of the "native's" point of view". Researchers can't follow all actors everywhere, therefore, they need to use their skills, experience, and judgement, like other qualitative research, to determine the starting point, the actors to follow, and where to cut the network. As a PhD student, I am also constrained by time and cost and as I am using ANT, I kept the following words by Latour in my mind while collecting the data:

You ask me how to stop and I am just telling you that the best you will be able to do, as a PhD student, is to add a text - which will have been read by your advisors, maybe a few of your informants, and three or four fellow doctoral students-to a given state of affairs. Nothing fancy in that: just plain realism. (Latour, 2005,p.148)

\section{Research methods}

Given the nature of the research questions, which are theoretically informed by strings from ANT, two research methodologies have been employed in this thesis: literature review and case study. The first two essays employ literature review as a research methodology to answer the first two research questions (see page 4). The journals scanned, the period covered, the keywords used will be discussed in details in each essay (please see section research site and methodology in essay 1 and section research methodology in essay 2).

According to Lowe (2001,p.344), "using ANT as a research strategy puts a strong emphasis on empirical enquiry". This empirical orientation is indicated in this thesis in essay 3 and essay 4 which utilize case study as an appropriate approach for collecting empirical data. Initially, my understanding of the case study methodology coincided with the definition suggested by Yin (2009,p.18), namely, "a case study is an empirical inquiry that investigates a contemporary phenomenon in depth and within its real-life context, especially when the boundaries between phenomenon and context are not clearly evident". However, ANT radically challenges some of the assumptions mobilized in Yin's ideas about case study methodology. Hansen (2011,p.118) argues that:

According to ANT, phenomena are therefore real. However, their meanings and social roles are constantly reconstructed in practice each time they are mobilized. Reality or meaning is fluid and not something that is present in principle, which, in contrast, is what Yin assumes. Of course, ANT's assumptions of reality affect its conceptualization of methodology.

This doesn't mean that we can't use Yin's ideas in the studies informed by Latour's stream of theorising (e.g., Mouritsen and Thrane, 2006), however, we have to be careful, especially, about the role of the theory, the role of researcher, and presumptions of reality (see Hansen, 2011).

In February 2012, I sent a research proposal be e-mail to one of the UK's leading retailer, 
which operates hundreds of stores across the UK to carry and provide a wide selection of different products to thousands of customers, to request access for conducting my case study. This company was chosen based on the industry in which it is operating (i.e. retail industry), as there is a gap in accounting research within the retail context, its long term involvement in SC practices (more than 15 years), the generous access to information and data needed, and the company's willingness to put me in touch with its partners along the SC. After few hours from sending my proposal, I received a positive reply from the senior supply chain manager confirming that their acceptance. As I knew that I was going to start my research in April 2012, I used the period between getting the access and starting my research to review the published literature about the UK retailing sector (see essay 2). The reason is that, as an international student, I didn't have any clue about the UK retailing sector, its dynamics, key actors, etc. Reviewing the literature helped me to get an in-depth knowledge about this sector and to shape the points that I want to explore during my field research.

The field research initiated with a pilot study as a small-scale preliminary study. The aim is to capture pre-understanding of the case organization, to collect first-hand information to crystallise the key supply chain aspects (i.e. processes, workflow, actors, issues and challenges), and to identify the most appropriate actors to be interviewed. During the pilot study, I conducted interviews with the senior supply chain manager (two times), the business development manager, the finance managers, operation manager, and general manager. Also, I was also allowed to visit the retailer's premises (e.g. the headquarter, consolidation centres, distribution centres, stores, and service centres). During my field research I felt like a stranger. This can be attributed to cultural, social, and language differences. Although being a stranger was helpful for me to assimilate a lot of information and data without bias that stem from preconceptions (Yin, 2009), it was, sometimes, difficult for me to understand the lived meanings that the interviewees ascribe to their responses. I overcame this challenge by asking the same questions to different actors, if appropriate, asking the interviewees for clarification, consulting my supervisors, or asking my friends who are native speakers about the meaning of some words or sentences. The outcomes of the pilot study helped me to determine the interviewees for the main study and refine data collection plans with regard to the content of the data and the procedures to be followed (Yin, 2009).

The data for essay 3 and essay 4 were collected over a period of two years and ten months, from April 2012 to February 2015. Essay 3 deals with downstream SC activities, therefore, the focus is on the relationships between the retailer and its distribution companies and logistics service providers which are shaped by supply chain strategy. Essay 4 deals with upstream SC activities through studying one of SC practices which is referred to as category management. Therefore, the focus is on the relationship between the retailer and its key fish supplier (category captain) . I chose to study fish category, after discussions with senior SC manager at the retailer's premises. My decision was due to the intensive suppliers' involvement in managing this category compared to other categories and to the manifold challenges related to the fish SC that have to be tackled by the retailer and suppliers, such as the highly fluctuating supply and unstable demand; the stringent environmental, quality,

2 To obtain access, a confidentiality agreement had to be signed with the supermarket which guaranteed the company that np commercially sensitive information would be published or released. 
ethical standards; and willingness of the retailer and the supplier to offer generous access to the data needed. Therefore, I thought that fish category would provide an information-rich context that would reflect the challenging environment in which the retailer and the supplier work together to manage the category efficiently and effectively.

As a method, ANT acknowledges the use of multiple data sources as a way for strengthen a case, as suggested by Yin (Alvesson and Sköldberg, 2009; Hansen, 2011). Therefore, I collected the data via a variety of sources; interviews, observation, and documentary analysis. Semi-structured interviews were deemed appropriate for this research due its flexibility (Bryman and Bell, 2007). Using this type of interviews enabled me to vary the questions freely; to add new questions, amend the questions, or even to omit some questions depending on what is going on during the interview. Also, it helped me to understand the human actors' perceptions with regard to nonhuman actors and to what extent these nonhuman actors affect their actions. Depending on the outcomes of the pilot study, various actors from various areas within SC and from different companies along the chain were selected to reduce subjectivity.

As a method, ANT acknowledges the use of multiple data sources as a way for strengthen a case, as suggested by Yin (Alvesson and Sköldberg, 2009; Hansen, 2011). Therefore, I collected the data via a variety of sources; interviews, observation, and documentary analysis. Semi-structured interviews were deemed appropriate for this research due its flexibility (Bryman and Bell, 2007). Using this type of interviews enabled me to vary the questions freely; to add new questions, amend the questions, or even to omit some questions depending on what is going on during the interview. Also, it helped me to understand the human actors' perceptions with regard to nonhuman actors and to what extent these nonhuman actors affect their actions. Depending on the outcomes of the pilot study, various actors from various areas within SC and from different companies along the chain were selected to reduce subjectivity. The selected actors from the retailer were senior supply chain managers, business development manager, finance managers, general managers, analyst, and category managers and from the retailer's partners (other companies along the chain) operations manager, business support manager, head of operations, operation director, category managers, fish supply analyst, and account managers. The duration of each interview was between 70 and 180 minutes, and one of the senior supply chain managers was interviewed twice. Some of the interviews were digitally recorded and later transcribed, with the interviewees' permission, and shorthand notes were taken, which were particularly useful during the data analysis. Where interviewees did not give permission for recording due to perceived sensitivity of information, extensive hand written notes were taken during the interviews. Shortly after each interview, extended summaries were written up for subsequent analysis.

There are different issues associated with using interviews as a method for collecting data. One of the issues that I faced during my study is related to the selection of interviewees which derived by my judgement and the availability of actors. Also, doing a research about

${ }^{3}$ To preserve the anonymity promised to the participating companies:

- The retailer will be referred to as XYZ in essay 3 and as MOJO in essay 4;

- The key fish supplier will be referred to as Fish House in essay 4. 
supply chain makes it more difficult to cover all areas which limit the scope of interviews. However, I tried to make sure that the interviews represented various types of companies (suppliers, retailer, distribution companies, logistics service providers) engaged in SC and different areas to reduce the bias, as mentioned before. Another problem is related to the conflict in the responses of the interviewees. For example, as you will see in essay 4, the interviewees from the retailer believe that the systems and databases that are used to facilitate the relationships between the retailer and the suppliers are very helpful and great, while, the interviewees from the suppliers see the opposite. However, I believe that these kinds of conflicts enrich the discussions and can enhance knowledge production (Latour, 2005).

Another issue is related to the credibility of interview data as the responses of interviewees could be subject to bias, inaccurate articulation, or poor recall (Yin, 2009). Using other sources of data can help with this issue.

In addition to interviews, I was granted access to some SC meetings (face-to-face meetings or conference calls) as an observer where representatives from the retailer and logistics service providers or suppliers participate in these meetings. During these meetings, notes were taken, and I was allowed to participate in the discussions to some extent. I got the permission to visit the shop floor of many centres (e.g. consolidation centres, distribution centres, service centres) to observe how work is done and what actors do. Additional information was sourced from company documents. Many pertinent documents were collected, not only from the retailer, but also from their partners, such as performance reports, spreadsheets, presentation slides, templates. Many other secondary sources were collected, such as press release, articles, and professional institutions reports. This use of multiple sources of data is particularly important to provide the researcher with a wide range of information and to help reduce mono-method bias via the comparison of the various data sources and the alignment of the derived assessments (Ellinger et al., 2005; Kalof et al., 2008).

Although many researchers agree that data analysis stage should start after collecting all the data, other researchers believe that "collection and analysis are inexorably intertwined" (Marginson, 2008,p.332). I started to analyse the data during the period of data collection in order to gain an initial understanding of the data and identify themes across the data. I followed the manual approach to categorize the data and identify the themes as I found it more appropriate for me. Although the manual approach is time-consuming and makes the navigation and linking of data difficult, I think using computer assisted methods in qualitative data analysis can affect the quality and richness of the analysis as "the very ease, speed and power of the software have the potential to encourage ... the researcher to take shortcuts" (Spencer et al., 2003,p.208).

I began the analysis process by reading the recorded interviews transcriptions, unrecorded interviews summaries and notes, the notes I took from observations, and the documents collected as a way to connect the data that were collected from various sources and identify some preliminary themes and trying to link them with the notions of ANT and heterarchy that would explain these data. Notes were taken during the reading and ideas, which I 
regarded as pertinent to research questions were highlighted such as actors engaged in the construction of business plan, the construction of business plan, the diffusion of business plan throughout the supply chain (essay 3 ), the actors involved in fish category management, the activities and practices associated with category management, the challenges of CM (essay 4). Initially, I used these ideas to code the data. Then, ANT and heterarchy were revisited using the data collected in order to develop a coherent understanding of SC strategy and category management. As a result, the data were recoded according to themes that were derived from the theoretical frameworks adopted such as lateral translation of SC strategy, horizontal translation of SC strategy (essay 3), and the practices that constitutes CM as an illustrative heterarchical case which are structuring, coordinating, and performing (essay 4). I added quotations when I felt that interviewees' words and expressions could clarify some ideas more clearly than words I might use. I believe that the use of quotations can deepen our understanding and make the story life-like.

Ethics are part of the everyday practice of conducting research (Guillemin and Gillam, 2004). Therefore, ethical guidelines have been established for scholars and researchers by different bodies such as universities, governments, etc. that clarify what is or is not legitimate to do during the research process and to make sure that research participants are treated ethically (Neuman, 2007; Kalof et al., 2008) . To assure confidentiality and anonymity, the research participants were given a consent form to read carefully and sign before their participation in the research (see appendix 2). The identities of the interviewees were concealed when quotations added into the analysis to preserve their anonymity, and, instead, their jobs were used. The access to the recoded interviews and their transcriptions was password protected.

\section{Implications for the quality of research}

There is still a debate between researchers regarding how to evaluate the quality of qualitative research and whether the traditional criteria (i.e., reliability and validity) are relevant for assessing the quality of qualitative research (Bryman and Bell, 2007; Silverman, 2010). Some researchers argue that reliability and validity are not the key drivers of a good research as they may constrain the discovery of key insights and as a result not maximize the quality of the research (Riege, 2003). They argue that concerns for reliability and validity criteria arise on within qualitative research (Silverman, 2011). Other researchers argue that reliability and validity are suitable for assessing the quality of qualitative research; however, the meanings attributed to these two concepts are different. In quantitative research, reliability refers to "the extent to which an experiment, test or measurement yields the same result or consist measurements on repeated trials" (Silverman, 2011,p.360). Therefore, it deals with the idea of replicability. However, this is unlikely applicable to qualitative research. According to Neuman (2007,p.119):

Most qualitative researchers resist the quantitative approach to reliability, which they see as a cold, fixed mechanical instrument that one repeatedly injects into or applies to some static lifeless material. Qualitative researchers consider a range of data sources and employ multiple measurement methods. They accept that

\footnotetext{
${ }^{4}$ I got an ethical approval from the University of Hull before conducting the case study.
} 
different researchers or that researchers using alternative measures will get distinctive results. This is because qualitative researchers see data collection as an interactive process in which particular researchers operate in an evolving setting and the setting's context dictates using a unique mix of measures that cannot be repeated.

Therefore, some qualitative researchers suggest different ways to satisfy the criterion of reliability. Guba and Lincoln (1994) argue that reliability can be achieved through providing an audit trail, as a form of methodological transparency, in which researcher document his/her procedure to reach what he/she has reached. This should include the formulation of the research problem (as discussed in this thesis in the introduction and each essay), research methodology, methods, and research participants (discussed in the introduction), documents collected, observation notes, interview transcriptions, notes, and summaries (available with the researcher), and the analysis of data (discussed in each essay). Moisander and Valtonen (2006,p.27) added that researchers should also pay attention to theoretical transparency by making "explicit the theoretical stance from which the interpretation takes place" because "theoretical framework produces particular interpretations and exclude others" (the theoretical frameworks, ANT and heterarchy, used and justifications for using them had been discussed in the introduction and in each essay. Silverman (2011,p.361) uses the term 'low-inference descriptors' to address the reliability in qualitative research and which involves "recording observations in terms that are as concrete as possible, including verbatim accounts of what people say". He focused on how different sources of data (e.g., interviews, observation, and textual analysis) can achieve low-inference descriptors, and, in turn, satisfies reliability criteria. According to Silverman (2011), with regard to interviews, low-inference descriptors can achieved through digitally recording interviews (many of the interviews conducted were digitally recorded and when recording was not possible, extensive hand-written notes were taking during interviews and, then, extended summaries were written up shortly after each interview as discussed before), careful transcriptions of recorded interviews according to the needs of reliable analysis (the transcription was done by the researcher and interviews had been transcribed in full), and presenting long extracts of data (relevant quotations were included while presenting the findings in essay 3 and essay 4). For observation, notes were taken at the time and, then, shortly after each session, extended notes were written up. According to Silverman (2011,p.364), textual data are more reliable than data collected from other sources because "when you are dealing with a text, the data are already available, unfiltered through the researcher's fieldnotes". In this thesis, I collected a variety of documents from the retailer, its partners, in addition to the internet.

Validity refers to "the extent to which the data are in some sense a 'true' reflection of the real world" (Scapens, 2008,p.268). In qualitative research, validity means truthful. According to Neuman (2007,p.120), "most qualitative researchers concentrate on ways to capture an inside view and provide a detailed account of how those being studied feel about and understand events". Two tactics were employed in this thesis to satisfy the criterion of validity. Acknowledged by ANT and heterarchy, multiple methods of data collection (triangulation) were utilized (interviews, observations, and documentary analysis). I found that the data, although collected from different sources, corroborate one another. Also, to be 
more confident about the data, I sent the case study draft, prior to incorporating the theoretical framework to be understandable, to the senior supply chain manager of the retailer and made some useful modifications based on his feedback.

\section{Conclusion}

In conclusion, I can assert that ANT is useful for a qualitative researcher as a specific epistemological approach. That is the social constructionist approach through which a researcher may emerge with actors and their networks, and with findings about his subject matter. This construction starts associating with actor after actor and with their network of networks. People, their meetings, objects, techniques, methods, designs, programmes, plans, strategies, forms, and software packages become an assemblage through this network building. Rather than being based on a pre-determined hard framework, this network building has allowed me to understand how and why supply-chains produce different management controls, performance measurements, and accounting practices. This also helped me understand how heterarchical tendencies are being developed as opposed to perennial hierarchical forms of organizations. All this is not a result of any technical superiority of supply-chains, logistics or category management but a result of the above social construction. My vital experience about this is that the employment of qualitative research can only make the path to this social construction. However, this is not realist but relativistic in relation to the situation we face, the context we study and the issues we address. Future researchers then find a different assemblage which stems from another form of social construction.

\section{References}

Alvesson, M. \& Sköldberg, K. (2009) Reflexive methdology: New vistas for qualitative research, London, SAGE Publications Ltd.

Amsterdamska, O. (1990) Surely you are joking, monsieur latour! Science, Technology, \& Human Values, 15, 495-504.

Boltanski, L. \& Thévenot, L. (2006) On justification: Economies of worth, Princeton, Princeton University Press.

Bryman, A. \& Bell, E. (2007) Business research methods, New York, Oxford University Press.

Burrell, G. \& Morgan, G. (1979) Sociological paradigms and organisational analysis, Hants, Ashgate Publishing Limited.

Callon, M. (1986) Some elements of a sociology of translation: Domestication of the scallops and the fishermen of st brieuc bay. In: Law, J. (ed.) Power, action and belief: A new sociology of knowledge? London: Routledge \& Kegan Paul plc.

Callon, M. (1991) Techno-economic networks and irreversibility. In: Law, J. (ed.) $A$ sociology of monsters: Essays on power, technology and domination. London: Routledge. 
Callon, M. (1993) Variety and irreversibility in networks of technique conception and adoption. In: Foray, D. \& Freeman, C. (eds.) Technology and the wealth of nations: The dynamics of constructed advantage. London: Pinter.

Callon, M. (1999) Actor-network theory - the market test. In: Law, J. \& Hassard, J. (eds.) Actor network theory and after. Oxford: Blackwell Publishers.

Collins, H. \& Yearley, S. (1992) Epistemological chicken. In: Pickering, A. (ed.) Science, practice and culture. Chicago: University of Chicago Press.

Ellinger, A. D., Watkins, K. E. \& Marsick, V. J.(2005) Case study research methods In: Swanson, R. A. \& Holton, E. F. (eds.) Research in organizations: Foundations and methods of inquiry San Francisco, California: Berrett-Koehler publisher, Inc.

Free, C. (2008) Walking the talk? Supply chain accounting and trust among uk supermarkets and suppliers. Accounting, Organizations and Society, 33, 629-662.

Guba, E. G. \& Lincoln, Y. S. (1994) Competing paradigms in qualitative research. In: Denzin, N. K. \& Lincoln, Y. S. (eds.) Handbook of qualitative research. Thousand Oaks,CA: SAGE Publications Ltd.

Guillemin, M. \& Gillam, L. (2004) Ethics, reflexivity, and "ethically important moments" in research. Qualitative Inquiry, 10, 261-280.

Hansen, A. (2011) Relating performative and ostensive management accounting research. Qualitative Research in Accounting \& Management, 8, 108-138.

Hassard, J. \& Wolfram Cox, J. (2013) Can sociological paradigms still inform organizational analysis? A paradigm model for post-paradigm times. Organization Studies.

Hull, R. (1999) Actor network and conduct: The discipline and practices of knowledge management. Organization, 6, 405-428.

Justesen, L. \& Mouritsen, J. (2011) Effects of actor-network theory in accounting research. Accounting, Auditing \& Accountability Journal, 24, 161-193.

Kalof, L., Dan, A. \& Dietz, T. (2008) Essentials of social research, Berkshire, Open University Press/ McGraw-Hill Education.

Kellogg, K. C., Orlikowski, W. J. \& Yates, J.(2006) Life in the trading zone: Structuring coordination across boundaries in postbureaucratic organizations. Organization Science, $17,22-44$.

King, R. P. \& Phumpiu, P. F. (1996) Reengineering the food supply chain: The ecr initiative in the grocery industry. American Journal of Agricultural Economics, 78, 1181-1186. 
Latour, B. \& Woolgar, S. (1979) Laboratory life: The social construction of scientific facts, London, Sage.

Latour, B. (1986) The powers of association. In: Law, J. (ed.) Power, action and belief: A new sociology of knowledge? London: Routledge \& Kegan Paul.

Latour, B. (1987) Science in action: How to follow scientists and engineers through society, Cambridge, Harvard University Press.

Latour, B. (1988) b. The politics of explanation: An alternative. In: Woolgar, S. (ed.) Knowledge and reflexivity: New frontiers in the sociology of knowledge. London: SAGE Publications.

Latour, B. (1990) Drawing things together. In: Lynch, M. \& Woolgar, S. (eds.) Representation in scientific practice. Cambridge, MA: MIT Press.

Latour, B. (1991) Technology is society made durable. In: Law, J. (ed.) A sociology of monsters: Essays on power, technology and domination London/New York: Routledge.

Latour, B. (1996) On actor-network theory: A few clarifications. Soziale Welt, 47, 369-381.

Latour, B. (1999) Pandora's hope: An essay on the reality of science studies, Cambridge, MA/London, Harvard University Press.

Latour, B. (2004) Politics of nature: How to bring the sciences into democracy, Cambridge, MA, Harvard University Press.

Latour, B. (2004) Why has critique run out of steam? From matters of fact to matters of concern. Critical Inquiry, 30, 225-248.

Latour, B. (2005) Reassembling the social: An introduction to actor-network-theory, New York, Oxford University Press Inc.

Latour, B. (2008) What is the style of matters of concern?, Amsterdam, Van Gorcum.

Law, J. \& Hassard, J. (1999) Actor network theory and after, Oxford, Blackwell Publishers.

Law, J. (1991) Introduction: Monsters, machines and sociotechnical relations. In: Law, J. (ed.) A sociology of monsters: Essays on power, technology and domination. London: Routledge.

Law, J. (1992) Notes on the theory of the actor-network: Ordering, strategy, and heterogeneity. Systems practice, 5, 379-393.

Law, J. (2000) Notes on the theory of the actor-network: Ordering, strategy, and heterogeneity. In: Staff, W. O. B. (ed.) Organizational studies: Critical perspectives on 


\section{THE CASE OF CASE STUDY METHODOLOGY \\ WITH ACTOR NETWORK THEORY \\ Samar Elsayad}

business and management. London: Routledge.

Lowe, A. (2001) After ant - an illustrative discussion of the implications for qualitative accounting case research. Accounting, Auditing \& Accountability Journal, 14, 327-351.

Marginson, D. (2008) The case study, the interview and the issues: A personal reflection. In: Humphrey, C. \& Lee, B. (eds.) The real life guide to accounting research: A behind the scenes view of using qualitative research methods. Oxford: Elsevier Ltd.

McLean, C. \& Hassard, J. (2004) Symmetrical absence/symmetrical absurdity: Critical notes on the production of actor-network accounts. Journal of Management Studies, 41, 493-519.

Miller, P. 1997. The multiplying machine. Accounting, Organizations and Society, 22, 355-364.

Moisander, J. \& Valtonen, A. (2006) Qualitative marketing research: A cultural approach, London, SAGE Publications Ltd.

Mouritsen, J. \& Thrane, S. (2006) Accounting, network complementarities and the development of inter-organisational relations. Accounting, Organizations and Society, 31, 241-275.

Neuman, W. L. (2007) Basics of social research: Qualitative and quantitative approaches, Boston, Pearson Education, Inc.

Riege, A. M. (2003) Validity and reliability tests in case study research: A literature review with "hands-on" applications for each research phase. Qualitative Market Research: An International Journal, 6, 75-86.

Rona-Tas A. (2011) The uses of uncertainty. Socioeconomic Review, 9, 597-612.

Rönnbäck, L., Holmström, J. \& Hanseth, O. (2007) It-adaptation challenges in the process industry: An exploratory case study. Industrial Management \& Data Systems, 107, 1276-1289.

Ryan, B., Scapens, R. W. \& Theobold, M. (2002) Research method and methodology in finance and accounting, London, Thomson.

Scapens, R. W. (2008) Doing case study research. In: Humphrey, C. \& Lee, B. (eds.) The real life guide to accounting research: A behind the scenes view of using qualitative research methods. Oxford: Elsevier Ltd.

Silverman, D. (2010) Doing qualitative research : A practical handbook, London, SAGE Publications Ltd.

Silverman, D. (2011) Interpreting qualitative data, London, SAGE Publications Ltd. 
Spencer, L., Ritchie, J. \& William, O. C. 2003. Analysis: Practices, principles and processes. In: Ritchie, J. \& Lewis, J. (eds.) Qualitative research practice: A guide for social science students and researchers. London: SAGE Publications Ltd.

Stark, D., Beunza, D., Girard, M. \& Lukács, J. (2009) The sense of dissonance, Princeton, Princeton University Press.

Wickramasinghe, D. \& Alawattage, C. (2007) Management accounting change: Approaches and perspectives, Oxon, Routledge.

Yin, R. K. (2009) Case study research: Design and methods, Thousand Oaks, California, SAGE Publications, Inc. 